\title{
Trait-based predation suitability offers insight into effects of changing prey communities
}

\author{
Benjamin Weigel ${ }^{\text {Corresp., }}{ }^{1,2}$, Erik Bonsdorff ${ }^{1}$ \\ 1 Environmental and Marine Biology, Faculty of Science and Engineering, Åbo Akademi University, Turku, Finland \\ ${ }^{2}$ Research Centre for Ecological Change, Organismal and Evolutionary Biology Research Programme, University of Helsinki, Helsinki, Finland \\ Corresponding Author: Benjamin Weigel \\ Email address: benjamin.weigel@helsinki.fi
}

Increasing environmental pressures and human impacts are reshaping community structures and species interactions throughout all trophic levels. The morphological and behavioural characteristics of species communities contain key ecological information on why prey species appear attractive to predators but are rarely applied when exploring predator-prey relationships. Expanding our knowledge on how changing prey communities can alter the food resource suitability for predators is vital for understanding predator-prey dynamics in changing ecosystems. Detailed predator diet data are commonly restricted to commercially important species and often not available over long temporal scales. To find out whether structural changes of prey communities impact the food resource suitability for predator communities over space and time, we apply a novel framework to describe and interpret changes in predator diet-suitability based on predation-relevant traits of prey. We use information on described feeding links from the literature to compile the prey spectrum for each predator and subsequently translate the prey-species into a prey-trait spectrum. For each predator, we then calculate a frequency-based prey-trait affinity score and relate it to the available food resource pool, the community weighted means of prey traits (CWM), resulting in a prey-suitability measure. We aim to reveal whether a described multi-decadal change in the community structure of zoobenthos had an impact on the food suitability for the benthic feeding fish in a coastal system of the Baltic Sea. We assess the direction of change in resource quality from the perspective of benthic-feeding fish and describe predator-specific responses to examine which species are likely to profit or be disadvantaged by changes in their prey spectrum. Furthermore, we test the relationship between functional diversity of prey communities and food suitability for predators, and whether predation linkage-structures are affected through prey community-changes. Our results show that changes in zoobenthic communities had a positive effect on the food suitability for most benthic-feeding fish, implying more suitable food resources. Speciesspecific responses of predators suggest varying plasticity to cope with prey assemblages 
of different trait compositions. Additionally, the functional diversity of zoobenthos had a positive effect on the food suitability for predator fish. The changing trait compositions of prey influenced the predator-prey linkage-structure, indicating varying specialisation of benthic feeding fish toward available food resources. Our findings suggest that changing morphological characteristics of prey can impact food resource suitability features for its predators. This approach enables long-term evaluation of prey quality characteristics where no detailed diet data is available and allows for cross-system comparison as it is not relying on taxonomic identities per se. 


\section{Trait-based predation suitability offers insight into effects of}

\section{2 changing prey communities}

3

4 Benjamin Weigel ${ }^{1,2}$ and Erik Bonsdorff ${ }^{1}$

$5{ }^{1}$ Environmental and Marine Biology, Faculty of Science and Engineering, Åbo Akademi

6 University, FI-20520 Turku, Finland

$7 \quad 2$ Research Centre for Ecological Change, Organismal and Evolutionary Biology Research

8 Programme, University of Helsinki, P.O. Box 65, FI-00014 Helsinki, Finland

9

10 Corresponding Author:

11 Benjamin Weigel ${ }^{1,2}$

12 Viikinkaari 1, Helsinki, P.O. Box 65, FI-00014, Finland

13 Email address: benjamin.weigel@helsinki.fi 


\section{Abstract}

15

16

17

18

19

20

21

22

23

24

25

26

27

28

29

30

31

32

33

34

35

36

37

38

39

40

41

42

43

44

Increasing environmental pressures and human impacts are reshaping community structures and species interactions throughout all trophic levels. The morphological and behavioural characteristics of species communities contain key ecological information on why prey species appear attractive to predators but are rarely applied when exploring predator-prey relationships. Expanding our knowledge on how changing prey communities can alter the food resource suitability for predators is vital for understanding predator-prey dynamics in changing ecosystems. Detailed predator diet data are commonly restricted to commercially important species and often not available over long temporal scales. To find out whether structural changes of prey communities impact the food resource suitability for predator communities over space and time, we apply a novel framework to describe and interpret changes in predator dietsuitability based on predation-relevant traits of prey. We use information on described feeding links from the literature to compile the prey spectrum for each predator and subsequently translate the prey-species into a prey-trait spectrum. For each predator, we then calculate a frequency-based prey-trait affinity score and relate it to the available food resource pool, the community weighted means of prey traits (CWM), resulting in a prey-suitability measure. We aim to reveal whether a described multi-decadal change in the community structure of zoobenthos had an impact on the food suitability for the benthic feeding fish in a coastal system of the Baltic Sea. We assess the direction of change in resource quality from the perspective of benthic-feeding fish and describe predator-specific responses to examine which species are likely to profit or be disadvantaged by changes in their prey spectrum. Furthermore, we test the relationship between functional diversity of prey communities and food suitability for predators, and whether predation linkage-structures are affected through prey community-changes. Our results show that changes in zoobenthic communities had a positive effect on the food suitability for most benthic-feeding fish, implying more suitable food resources. Species-specific responses of predators suggest varying plasticity to cope with prey assemblages of different trait compositions. Additionally, the functional diversity of zoobenthos had a positive effect on the food suitability for predator fish. The changing trait compositions of prey influenced the predator-prey linkage-structure, indicating varying specialisation of benthic feeding fish toward available food resources. Our findings suggest that changing morphological characteristics of prey can impact food resource suitability features for its predators. This approach enables long- 
45 term evaluation of prey quality characteristics where no detailed diet data is available and allows

46 for cross-system comparison as it is not relying on taxonomic identities per se.

47

\section{Introduction}

49 Community reorganizations, due to natural and anthropogenic pressures on the environment, not 50 only reshuffle species compositions, but also affect species interactions and trophic dynamics 51 (Tylianakis et al., 2008). What makes prey species suitable and/or favourable for their predators 52 has been a central question in ecology for over half a century (e.g. Dice 1949; Pyke, Pulliam \& 53 Charnov 1977) and with accelerating rates of changing communities and shifting interactions 54 (e.g. Harley et al. 2006; Both et al. 2009; Schmitz \& Barton 2014), it is still a relevant one. 55 Besides purely size-structured approaches (Kerr, 1974; Gravel et al., 2013), the 'who eats whom' 56 is usually described through empirical observations such as gut content analysis (Hyslop, 1980;

57 Hinz, Kröncke \& Ehrich, 2005; Baker, Buckland \& Sheaves, 2014), stable isotope measurements 58 (Fry \& Sherr, 1989; Quillien et al., 2016), or fatty acid measurements (Iverson, 2009; Kelly \& 59 Scheibling, 2012), resulting in species-based trophic links. This type of data is usually 60 temporally restricted and often limited to commercially relevant species due to high sampling and analysis efforts as well as costs. Although a pure taxonomy-based approach is the fundament of linking predator and prey, it neglects the key ecological information on why a species appears relevant as prey in the first place. Instead of being determined by taxonomic classifications, predation is more likely to be driven by the morphological and behavioural characteristics of a prey species than by its name (Spitz, Ridoux \& Brind'Amour, 2014). Hence, taxonomic affiliations of species offer only restricted information regarding their suitability as prey or their ecological role in general. During the past decades, the perception of taxonomic limitations in answering ecological questions has led to a steep increase in studies applying different measures linked to functional traits of species, rather than taxonomic related indices, when investigating ecosystem processes or species interactions (Tilman et al., 1997; Cadotte, Carscadden \&

71 Mirotchnick, 2011; Mouillot et al., 2011; Gagic et al., 2015).

72 Although it seems straightforward to include morphological and behavioural attributes 73 describing prey, this approach has so far been applied in relatively few studies. Using trait-based 74 approaches in the framework of feeding ecology has contributed significantly to a more complete understanding of predator-prey relationships and prey selectivity (De Crespin De Billy \& 
76 Usseglio-Polatera, 2002; Rossberg, Brännström \& Dieckmann, 2010; Nagelkerke \& Rossberg, 77 2014; Rodríguez-Lozano et al., 2016) through prey vulnerability traits, predator foraging traits, 78 and the interaction of both prey and predator traits (Klecka \& Boukal, 2013; Green \& Côté, 79 2014; Spitz, Ridoux \& Brind'Amour, 2014).

80 In dynamically changing ecosystems, strong environmental drivers, human impacts, and invasive 81 species may rapidly alter community characteristics and biotic interactions (Collie, Wood \& 82 Jeffries, 2008; Walther, 2010; Johnson et al., 2014; Weigel et al., 2015). Bottom trawl fishing, 83 for example, has been highlighted as one particular human pressure that can impact the 84 composition of benthic prey communities, leading to altered predator conditions by changing the 85 prey availability (Hiddink et al., 2016; Hinz et al., 2017). Trait-based approaches seem to be a 86 promising tool to assess changing food conditions on community levels (Weigel, Blenckner \& 87 Bonsdorff, 2016). Yet, to our knowledge, there is no available framework to evaluate how 88 changing prey may affect the suitability of food resources of a predator community over time and/or space. Here we suggest a novel concept to assess how changes in prey communities may influence food resource conditions for their predators based on a trait-suitability measure linked to the community weighted mean traits (CWM) of prey. We apply our approach on a marine coastal system in the Baltic Sea, to find out if changes in zoobenthos community structure influenced the food resource suitability for the benthic feeding fish community. While we focus on the link between zoobenthic prey and benthic-feeding fish in this study, the concept is applicable to all predator-prey systems. The broad spectrum of phenotypic variation in zoobenthos makes it an ideal group to illustrate our approach. For example, many zoobenthos species can be inaccessible for their potential predators as they may be buried too deep in the sediment, have strong physical protection or are not within the right size spectrum to be consumed. In contrast, other zoobenthos may serve as easy prey items for visual hunters when occurring epibenthically, i.e. on or just above the sediment surface, and being motile with no physical protection such as hard shells.

The zoobenthic communities in our study system have undergone significant changes in species composition as well as in their functional structure, i.e. CWM, over the past four decades (Weigel, Blenckner \& Bonsdorff, 2016). These long-term changes in zoobenthos CWM indicate significant alterations of the morphological and behavioural characteristics of prey communities from a predator perspective, which could result in altered food resource conditions for 
107 benthivorous fish. With currently no other available means to evaluate or predict how the

108 observed functional and structural changes of the zoobenthos community may affect the benthic

109 feeding fish through changed resource availability, particularly over long temporal scales (in our

110 case several decades), we calculate a trait-based predation suitability measure for coastal fish and

111 examine how changes in CWM of the prey community alter the food resource suitability over

112 space (sheltered and exposed coastal zones) and time (40 years). For building the trait-suitability

113 measure, we first compile information on the prey species spectrum for each predator from the

114 literature. In the following step we translate the species into their trait spectrum, reflecting

115 predation relevant traits. The frequency of specific traits in the diet results in predation affinity

116 scores, which are ultimately related to the available food resource pool (CWM).

117 In a system where the link between zoobenthos and fish is strong (Mattila \& Bonsdorff, 1988;

118 Snickars, Weigel \& Bonsdorff, 2015), we hypothesise that changes in the predation relevant

119 traits of prey communities result in altered resource suitability for the predators. Our aim is to

120 answer whether structural changes of the zoobenthos community, based on predation-relevant

121 morphological and behavioural characteristics, influence the suitability of the food resource pool

122 for the predator assemblage. We evaluate which benthic feeding fish species are likely to benefit

123 from the functional changes of the zoobenthos and which are more likely to experience lower

124 matching food availability. We further investigate the relationship between the functional

125 diversity of prey communities and the food resource suitability for predators, and lastly, whether

126 altered functional compositions of prey communities may affect the predation linkage structure.

127

128 Material and methods

129 Study system and predator-prey communities

130 Our study area comprises coastal zones of the Åland archipelago in the northern Baltic Sea

$131\left(60^{\circ} 15^{\prime} \mathrm{N} ; 19^{\circ} 55^{\prime} \mathrm{E}\right)$. The complex land- and seascape form a heterogeneous habitat,

132 encompassing thousands of islands with sheltered bays, exposed open coasts, soft as well as hard

133 substratum, and thus create a multitude of general coastal types. The link between zoobenthos

134 and fish is strong in this area (Mattila \& Bonsdorff, 1988) as most of the present fish ( $95 \%)$ are

135 benthivorous during at least part of their life cycle (Snickars, Weigel \& Bonsdorff, 2015), and

136 thus to a significant part rely on the zoobenthic food resource. In our analysis we included eleven

137 benthic feeding fish species of the Åland coastal zones, which have been continuously recorded 
138 during long-term coastal fish surveys in the study area. Details of the survey method and gear are

139 described by Snickars et al. (2015). As our study focusses on a qualitative approach to food-

140 resource availability for predators, the continuous presence of included fish species over the past

14130 years was set to be a sufficient criterion for their inclusion and relevance in the present study.

142 The fish community includes species of marine as well as freshwater origin, with both

143 classifying either as cold or warm water species (Tab. 1), which exemplifies our study system as

144 a model area that can be related to marine, brackish-estuarine and freshwater systems in

145 environmental settings ranging from sub-arctic (cold water) to boreal (warm) areas.

146 Zoobenthos communities (prey) included in this work have been monitored over a 40-year time

147 frame from 1973-2013 in the same area as the benthic-feeding fish to assure the direct linkage

148 between predator and prey. We included community data from 16 sites comprising two different

149 coastal exposure-zones, sheltered and exposed areas, both representing eight sites. (Weigel,

150 Blenckner \& Bonsdorff, 2015, 2016). The exposure zones provide a proxy for habitat

151 characteristics that have shown to structure the composition and diversity of zoobenthic

152 communities around the Åland Islands, reflecting the exposure to wind and waves, the proximity

153 to land as well as depth (Weigel et al., 2015). We included sites that were sampled in 1973,

154 1989, 2000 and 2013. Each sampling occasion comprised five replicate Ekman-grab samples

155 (289 $\mathrm{cm}^{2}$ per sample) at each site, which were directly fixed in a 4\% buffered formaldehyde

156 solution and later identified in the lab to their lowest practical taxonomic unit under a stereo

157 microscope. For further detailed information on the sampling protocol refer to Weigel et al.

158 (2015).

159

160 Trait-based diet spectrum

161 We selected 7 predation-relevant traits for benthivorous fish that reflect quality aspects of

162 zoobenthos as a food resource, covering morphological and behavioural characteristics related to

163 the availability, susceptibility, and palatability of the prey. All 7 traits are categorical and contain

164 a total of 24 categories (Tab. 2). Applied traits were collected from Törnroos and Bonsdorff

165 (2012) and Weigel et al. (2016). As many fish species are visual hunters, we included one new

166 trait, further characterising zoobenthic prey, indicating if a species is protruding the sediment

167 ('sediment protruding') based on expert judgement. 
168 For the included fish species, we calculated a species-specific trait-based diet spectrum (DS)

169 reflecting the affinity of a predator to specific prey traits and built on the following steps: First,

170 we collected information from studies and open data sources reporting on the prey spectrum for

171 each predator fish species, resulting in data that include the zoobenthos taxa that the predator

172 utilizes as prey (Supplementary materials, Tab. S1). Based on the presence/absence data of prey

173 species in the predator diet spectrum, we built a predator-prey matrix (PP) of every predator $i$

174 and prey $j$ (Fig. $1 \mathrm{~A}$ ), where 1 indicates that predator $i$ is feeding on prey $j$ and 0 indicates that $i$ is

175 not feeding on $j$ (Supplementary materials, Tab. S2). Second, we built a prey trait matrix (T),

176 including the selected traits described above (Tab. 2), for all prey species $j$ and all traits $k$ (Fig.

177 1B), where 1 indicates that prey species $j$ expresses trait $k$ and 0 indicates that prey species $j$ is

178 not showing trait $k$ (Supplementary materials, Tab. S3). The prey trait matrix is built for every

179 predator $i$ and its specific diet spectrum. Third, we calculate the predator specific trait Diet

180 Spectrum $D S$ (Fig. 1C) as the sum of each prey trait category over all prey species in relation to

181 the total number of species in each predator's diet (Fig. 1) with:

$182 D S_{i, k}=\frac{\sum_{i=1}^{n} P P_{i, j} \times T_{j, k}}{\sum_{j=1}^{n} P P_{i, j}}$ (Equation 1)

183 A trait category being present in every prey item of a predator would therefore result in

184 maximum predation affinity of 1 , while another trait category being present in only half of the

185 prey items would result in a score of 0.5 .

186

\section{Food resource suitability proxy}

188 We calculated the potential prey resource availability for predators as the community weighted means of trait category expressions (CWM). Including 16 sites in every sampling year (1973, 1989, 2000, 2013), all CWM values are based on abundance-weighted traits of zoobenthos, with mean species abundances comprising 5 replicate samples per site (see Weigel, Blenckner \& Bonsdorff, 2016). We used the 'FD' library (Laliberté, Legendre \& Shipley, 2014) in the R environment for statistical computing ver. 3.3.0 (R Development Core Team, 2013) to calculate all CWM-values and subsequently standardized them to range between 0 and 1. Relating the trait-based diet spectrum $(D S)$ of benthivorous fish to the potential resource pool of zoobenthic prey, we developed a predator-specific proxy for prey Resource Suitability $R S$ based on $D S$ and the present prey community structure (community weighted mean traits, CWM) at 
198 each site and year and for all traits, by calculating the product of the predator specific diet

199 spectrum and the trait-based resource availability:

$200 R S_{i, k}=\sum_{k=1}^{t} D S_{i, k} * C W M_{k} \quad$ (Equation 2)

201 with $R S_{i, k}$ being the food Resource Suitability for predator $i$ and trait $k$, resulting from the 202 predator-specific diet spectrum for prey traits $D S_{i, k}$ as calculated above, and $C W M_{k}$ being the 203 community-weighted mean of the trait category expression at each site and year. The food 204 resource suitability proxy $R S$ provides a likelihood measure, bound between 0 and 1 , for 205 predators to encounter suitable food resources based on the prey traits. Suitability values close to 2061 suggest a high prey trait availability for predators in combination with a high affinity in the diet 207 spectrum to a particular trait, and therefore results in a high likelihood of the predator 208 encountering the suitable food resource. Values closer to zero reflect a low likelihood when an 209 affinity to a trait in the diet spectrum is low and/or the resource availability (CWM) is low.

210 To test whether the food suitability for the predator community changed over time (1973-2013)

211 and space (sheltered and exposed sites), we built a generalised linear mixed effect model

212 (GLMM) with the resource suitability value $R S$ as response variable (Supplementary materials,

213 Workflow and results of GLMM analysis). As fixed factors we included 'year' and 'exposure'

214 and as random factors we included 'sites', 'fish species' and 'traits' to account for non-

215 independence of observation from the same stations, the same predator and traits over time. We 216 analysed the model using the 'nlm4' library (Bates et al., 2015) in connection with the

217 'nlmerTest' library (Kuznetsova, Brockhoff \& Christensen, 2016) to get significance estimates

218 of model terms. To normalize the distribution of model residuals, all food resource suitability

219 values were $\log$ transformed $(\log (x+0.01))$ prior to the analysis and subsequently standardized to 220 zero mean and unit variance.

221 To shed light on how the food suitability proxy for each individual fish species varied over time 222 and space, we further analysed species-specific GLMMs, similar to the previous community223 based model, with year and exposure as fixed factors and sites and traits as random factors, to 224 account for non-independencies of observations within each species.

225

\section{Functional diversity and food resource suitability}


227 In the present analysis, functional diversity is considered as the diversity in distribution and 228 range of expressed functional traits (Petchey \& Gaston, 2006), with functional traits reflecting 229 morphological and behavioural characteristics of organisms being relevant from a predatory 230 perspective. We calculated the functional diversity of prey communities as Functional Dispersion 231 (FDis) after Laliberté and Legendre (2010). We chose FDis because it is unaffected by species 232 richness, takes species abundances into account and is capable of handling more traits than 233 species. The metric depicts the abundance-weighted mean distance of individual species to their 234 group centroid (all species of an assemblage) in a multivariate trait-space. FDis was calculated 235 for assemblages at every site sampled (eight sheltered, eight exposed) based on the mean 236 abundances of five samples, using the 'FD' library (Laliberté et al. 2014). We tested whether the 237 development in FDis changed over time by using a linear mixed-effect model with 'year' as 238 fixed factor and 'site' as random factor, to account for non-independency of observations from 239 the same sites over time. To reveal any relationship between functional diversity and food resource suitability $R S$, we fitted a linear model with FDis being the predictor covariate of $R S$.

\section{Predation linkage structure}

243 To find out whether predators show varying specialization and plasticity to the changing trait composition of prey assemblages over time and space, we built predator-prey bipartite interaction networks. Bipartite networks are essentially two-level food webs, in our case linking the zoobenthic prey with the benthivorous predator fish. Besides being applied for studying trophic interaction networks, they are commonly used in pollination webs and seed dispersal studies where every member of the first level is only connected to members of the second level while direct interactions within one level are considered unimportant (Dormann, Gruber \& Fruend, 2008). Here we used the CWM-values of the zoobenthic assemblages as lower trophic level and connected them with each predator fish, representing the higher trophic level. To account for the affinity of a predator to a prey trait, we weighted each prey-CWM at all stations and for all years with the species-specific diet suitability value in $D S$. We used two species-level indices to investigate changes in predation linkage structure over space and time. Proportional similarity provides a measure of predator specialisation and describes the dissimilarity between resource use and resource availability, i.e. how many of the prey traits are potentially fed on in relation to how many prey traits are present. Values of 1 indicate high generality of predators, 
258 where all the available food resources are theoretically also used/interacted with. Further, we

259 calculated the sum of interactions per species, describing the total number of links between

260 predator and food resource. All interaction networks and indices were calculated in the 'bipartite'

261 library (Dormann, Gruber \& Fründ, 2008; Dormann et al., 2009; Dormann, 2011) and the R

262 environment.

263

\section{Results}

\section{Predation profile based on prey traits}

266 Our results demonstrate species-specific feeding spectra of the studied eleven coastal fish species 267 and their affinity toward individual prey characteristics (trait categories) (Fig. 2). Furthermore, 268 our findings indicate that there is a resemblance in diet spectrum for a few trait-categories among 269 all fish species, showing a generally high affinity for medium sized, epibenthic and surface 270 crawling prey. However, the majority of traits are more variable regarding their predatory 271 affinity among species. By grouping the fish species according to their diet spectrum similarity, 272 we illustrate the relationship in trait-based predation patterns between the predator species (Fig. 273 2). One close grouping cluster comprises the species Coregonus lavaretus, Perca fluviatilis, 274 Platichthys flesus, Rutilus rutilus, showing very similar affinities over the entire trait spectrum. 275 While the four predators utilize all size classes, it is mainly the robust, hard and soft shelled as 276 well as species with no protection, living in the upper part of the sediment and crawling on the 277 surface which they have high affinities to. On the contrary, Triglopsis quadricornis, Clupea 278 arrengus and Gymnocephalus cernuus have more specific feeding size classes, not utilizing prey 279 classified as small. All three have no affinity to hard shelled prey. T. quadricornis has the highest 280 affinity for soft shelled species and is not utilizing any infaunal prey that is deeper than $2 \mathrm{~cm}$ 281 from the sediment surface (infauna top). It does however have a strong affinity to all prey 282 movement types. G. cernuus can utilize a broader range of prey protection types and has equally 283 high affinities to the environmental position of prey ranging from epibenthic to the deep infauna 284 ( $>5 \mathrm{~cm})$. C. harengus shows the highest affinity to bentho-pelagic prey among all species but 285 only utilizes prey with high energy content. Leuciscus idus and Abramis bjoerkna both are the 286 only predators of the assemblage not showing any affinity for large-sized prey or species with a 287 burrowing movement typ. Additionally both predators have the highest affinity to prey with no 288 protection (Fig. 2). 
290 Food resource suitability over space and time

291 Time had a significant effect on the overall food suitability for the benthic feeding predator 292 assemblage (Tab. 3). Thus, the suitability-proxy calculated as the product of affinity to and 293 availability of food resources (Eq. 2) first decreased towards 1989 (GLMM, $p<0.05$ ) and then 294 increased over time in the years 2000 (GLMM, $p<0.0001$ ) and 2013 (GLMM, $p<0.0001$ ) 295 compared to the values in 1973 (model intercept). There was no effect of exposure on the food 296 quality, implying no significant difference between sheltered and exposed areas (GLMM, $p=$ 297 0.669) (Tab. 3).

298 In accordance with the community model results, the species-specific models show that there is a 299 general trend for most of the fish species (9 out of 11) to experience a significantly positive 300 progression in food suitability over time (Fig. 3, Supplementary materials, Workflow and results 301 of GLMM analysis). This pattern is gradual with generally highest model estimates in 2013 but

302 303

304

305 306

307

308

309

310

311

312

313

314

315

316

317

318 319 shows different species-specific strength. However, there were species for which the food suitability did not improve. For example, food quality for Abramis bjoerkna showed a negative trend until after 2000 and only becomes positive in 2013 while not being significantly different from the suitability measure in 1973 at any point in time (Fig. 3). The food quality for Leucidus $i d u s$ also shows no significant increase and that of Triglopsis quadricornis decreased in 2013 compared to 2000. Although there is no significant effect of exposure on the food suitability, the model estimates for exposure show both marginal positive and negative trends for the different species (Fig. 3) (Supplementary materials, Workflow and results of GLMM analysis).

\section{Functional diversity - food suitability relationship}

The development of functional diversity of prey communities, calculated as FDis, showed an increasing trend over time, with a significant effect of year (GLMM, $p<0.001)$, displaying highest FDis-values and lowest within year variation in the two recent sample occasions (2000 and 2013), indicating a higher functionally diversity compared to the early 1970s and 80s (Fig. 4A). Furthermore, functional diversity (FDis) had a highly significant and positive effect on food suitability (lm, $p<0.0001$, ad. $\mathrm{r}^{2}=0.53$ ) of sampled prey communities (Fig 4B).

\section{Specificity and resource use of predators}


320 The total sums of interactions between predator and prey generally increased over time,

321 especially at exposed sites (Fig. 5A). This implies that the zoobenthos assemblages display a

322 higher number of suitable traits that the predator fish are able to utilize. For all eleven predator

323 fish species, the total sums of interaction are the highest in the two later years of the study, 2000

324 and 2013, a pattern particularly pronounced at exposed sites. Absolute values in the sums of

325 interaction at sheltered sites did not change considerably compared to the increasing tendency at

326 exposed sites (Fig. 5A).

327 The ratio between resource use and resource availability, the proportional similarity metric,

328 showed species specificity, revealing the grade of specialisation/generality of the predator in 329 relation to the present prey community (Fig. 5B). At the exposed sites, Abramis bjoerkna and

330 Leucidus idus showed a decrease in proportional similarity, implying a higher specialisation

331 towards the available food resource over time. Hence, following the changing prey traits, both

332 predators have less suitable traits to feed on and appear more specialized in relation to the food

333 resource pool. This pattern was, however, not reflected at the sheltered sites. The high generality-

334 values, in combination with minimal within year variation of Abramis brama, Osmerus

335 eperlanus, Perca fluviatilis and Platichthys flesus, show a high efficiency in available resource

336 use and a high generality of these predators regardless of the varying sum of interactions within

337 years and exposure groups (Fig. 5). The predator community generally displays relatively high

338 values of proportional similarity with Triglopsis quadricornis being the most specialised species

339 displaying the lowest values overall, which holds particularly true for exposed areas.

\section{Discussion}

342 Trait-based predation; concept and food suitability proxy

343 Predators select their prey irrespective of taxonomic identities but based on a multitude of

344 phenotypical characteristics, such as morphological, behavioural and life history traits

345 (Husseman et al., 2003; Klecka \& Boukal, 2013; Green \& Côté, 2014; Spitz, Ridoux \&

346 Brind'Amour, 2014; Rusch et al., 2015; Rodríguez-Lozano et al., 2016). In this study, we

347 applied a novel framework to describe predatory diet suitability based on predation-relevant

348 functional traits of prey. This approach facilitates the understanding on how changes in prey

349 communities may impact the food resource suitability for higher trophic levels, which can

350 potentially result in bottom-up cascades. Our method takes advantage of binary predator-prey 
351 links, i.e. the presence and absence of feeding links, collected from the literature, to create a trait-

352 based diet spectrum that reflects the affinity of a predator towards particular trait categories of a

353 prey species (Fig 1, 2).

354 Following this predator-specific measure, we highlight the composition as well as the theoretical

355 predation-affinity to prey traits (Fig. 2). The comparison of trait feeding affinities among species

356 highlights the similarities and dissimilarities in the food spectra of the predator assemblage. Fish

357 with a similar diet spectrum group close to each other. Close groupings of predators, i.e. species

358 having similarly affinities to prey traits, such as perch (Perca fluviatilis), flounder (Platichthys

359 flesus) and roach (Rutilus rutilus) (Fig. 2), could serve as an indication for resource competition

360 regarding their zoobenthic prey (Mattila \& Bonsdorff, 1988, 1989). This is in line with earlier

361 findings on interspecific competition among these three species (Persson, 1983; Lappalainen et

362 al., 2001). However, evaluating the impact of competition between the species on the food-

363 resource availability is outside the scope of this study, nonetheless the theory could support

364 future studies considering trait-based measures of interspecific competition.

365 To evaluate food suitability of a prey community, the measure of feeding affinity to prey traits

366 has to be related to the actual resource availability, i.e. the present prey community. As such,

367 community weighted mean traits (CWM) offer a meaningful link to the predator-prey diet

368 spectrum scores, capturing a quantitative measure of the abundance weighted average

369 community traits. It seems intuitive that high food resource suitability values, i. e. high affinity to

370 an available resource, suggests preferable food conditions over low suitability values. However,

371 disproportionate consumption rates in relation to prey abundance are also common, based on

372 dietary preference (Vadas, 1977; Almany \& Webster, 2004) and maximal energetic gain (Pyke,

373 Pulliam \& Charnov, 1977). In the here applied food suitability measure, predators are assumed to

374 consume the available resources following the proportion of their affinity scores, which includes

375 weighting morphological preferences derived from the observed diet spectrum. Yet, the

376 weighing based on presence/absence data does not reflect the different proportions of specific

377 prey items being ingested more or less frequently and potential ontogenic shifts in prey

378 preference are not considered when predator age classes are not taken into account.

379 Studying a system where long-term structural and functional changes of zoobenthic communities

380 have been described in detail (Weigel et al., 2015; Weigel, Blenckner \& Bonsdorff, 2016), we

381 found that the altered prey CWM had an effect on the food suitability of the predator assemblage 
382 over time, confirming our hypothesis. Weigel and colleagues (2016) described the major changes

383 in zoobenthic trait composition over time based on community changes in the sheltered and

384 exposed areas we also studied here. Detailing some of their findings and relating them to changes

385 in the here observed food suitability, they found that the changes in sheltered areas between 1989

386 and 2000 could be linked to decreasing proportions of hard-shell-protected and increasing

387 borrow-protected species, becoming more fragile, increasing in size with higher proportions of

388 large-sized species and increasing high-energy contents. Similarly, in exposed areas, changes

389 were linked to increased proportions of high-energy species and increasing soft shelled

390 protection. These particular changes in CWM can explain why the two species, L. idus and $A$.

391 bjoerkna did not show an increase in food suitability (Fig. 3) as neither displays an affinity for

392 large-sized and soft-shelled species. A. bjoerkna additionally showed no affinity for high energy

393 species and L. idus none for fragile species, both categories highlighted to have played a

394 significant role in the changing trait composition of the prey communities. Particularly the soft-

395 shelled increase can add to explain the highly significant increase in food suitability for $C$.

396 harengus and T. quadricornis which both have high feeding affinities towards this trait. For the

397 period comparing 2000 and 2013 on the other hand, the food suitability for T. qudricornis

398 decreased, which can be associated to higher proportions of the prey community being buried

399 deeper in the sediment (Weigel, Blenckner \& Bonsdorff, 2016). The overall increased food

400 suitability for nine out of the eleven coastal benthic-feeding fish (Fig. 3, Tab. 3) may have

401 contributed to the increase in total fish abundances (in catch per unit effort) since the mid-late

402 1990s in the same area despite an overall decrease in zoobenthic biomasses (Snickars, Weigel \&

403 Bonsdorff, 2015). While our framework centres on a bottom-up approach, aiming to answer how

404 changing prey communities affect predators, it is important to acknowledge that increasing

405 feeding pressures due to higher abundances of predators or changes in the predator species

406 composition may also structure the prey community and its biomass from the top down (Mattila

407 \& Bonsdorff, 1988; Olsson, Bergström \& Gårdmark, 2013; Hinz et al., 2017). Hence, scenarios

408 would be possible where the predators themselves would decrease the resource suitability by

409 diminishing the CWM of favourable food items.

410 Against our expectations, there was no significant spatial effect, i.e. sheltered or exposed areas,

411 on the prey suitability, although both areas showed significantly different progression pathways

412 regarding the zoobenthic CWM (Weigel, Blenckner \& Bonsdorff, 2016). This suggests no 
413 generality in the effect of changing functional compositions on the suitability-measure per se but

414 highlights the importance of particular traits in the food resource, depending on the predator

415 species and its diet spectrum (Fig. 2, 3).

416

\section{Functional diversity and prey suitability}

418 Communities with a high functional diversity are assumed to express a wide range of ecosystem

419 functions (Clark et al., 2012), supporting resilience towards environmental change (Folke et al.,

420 2004) and promoting the magnitude of ecosystem processes (de Bello et al., 2010). In the present

421 study, the functional diversity of prey communities, measured as FDis, increased over time

422 displaying highest absolute values and lowest variation in 2000 and 2013, while the earlier

423 sampling years showed a generally lower absolute FDis and a high within year variation

424 (Fig. 4A). Weigel and colleagues (2016) have linked the increased functional diversity to the

425 presence of the invasive polychaete non-native Marenzelleria spp, which seemingly promoted a

426 higher FDis. Although they applied a different set of functional traits, focussing on a broader set

427 of general traits than primarily predation relevant attributes as in this study, they observed a

428 similar pattern in the progression of FDis. This shows that the FDis pattern remains robust

429 despite the type of traits being applied.

430 The large within-year variation of FDis can be interpreted as a high spatial discrepancy of prey

431 traits at the assemblage level, with species ranging from a diverse set of different trait

432 combinations at some sites to very similar traits of an assemblage at others (Fig 4A, 1989).

433 Theory suggests that areas with low functional diversity of prey assemblages should display a

434 higher risk to predators for not finding suitable dietary traits. Whereas a high functional diversity

435 of prey would increase the spectrum of available prey traits and thus the chance, for a wider

436 range of predators, to encounter suitable food resources. Hence, a higher functional diversity

437 should support a higher resource suitability. Our results show that elevated FDis of prey

438 communities coincided with an increase in the food suitability for predators (Fig. 4B). This

439 relationship highlights the positive effect of diverse prey-traits on the food resource suitability

440 for predators and supports a positive functional diversity - ecosystem function relationship

441 (Hooper et al., 2005).

442 For specialist species, feeding only on a narrow range of prey items, high functional diversity

443 may be particularly important to ensure matching food items in a rapidly changing environment. 
444 Although the benthivorous fish in our study are mostly generalist, they still profit from a higher

445 FDis as the suitable food resource-range increases and therefore the number of possible

446 interactions between predator and prey (Fig. 5A).

447 Considering the role of the non-native polychaete Marenzelleria for the elevated and more stable 448 FDis values (Weigel, Blenckner \& Bonsdorff, 2016), as well as the observed positive FDis-food 449 suitability relationship (Fig. 4), our results suggest that Marenzelleria may feature prey attributes 450 that are generally favourable for the benthivorous fish community. Hence, since its establishment 451 in the early 1990s, Marenzelleria seems to act as supporting food item for coastal fish (Winkler 452 \& Debus, 1996).

453 A high functional diversity of prey communities supports a broad spectrum of available food 454 resources for predators and could hence serve as a valid approximation for food-quality 455 estimations as depicted in our results (Fig 3, 4).

456

457 Feeding specificity and plasticity of predators

458 The structure of food webs constitutes an important role for ecosystem properties (Pimm, 459 Lawton \& Cohen, 1991; Thébault \& Loreau, 2003) and has been linked to the functioning and 460 resilience of communities (Yen et al., 2016; Yletyinen et al., 2016). Understanding how changes 461 in prey communities affect the predation linkage structure of predator-prey networks, can thus 462 provide insight into the resilience of predators to fluctuating food resources, their plasticity to 463 adapt and their efficiency of resource utilisation.

464 In the present study, we show that an altered functional composition (CWM) of a prey 465 community may affect the predator-prey network structure and impact the degree of 466 specialisation of a predator toward the available food resource pool (Fig. 5). Although predators 467 showed generally high variability in the total sum of interactions (Fig. 5A), the ability to utilise 468 the present food resources remained stable for most of the predators, and in particular for $A$. 469 brama, O.eperlanus, P. fluviatilis, and P. flesus with close to zero variation within and among 470 years and exposure class (Fig. 5B), suggesting a high plasticity in coping with changing prey 471 communities. In contrast, species that show decreasing proportional similarity over time, such as 472 A. bjoerkna and L. idus, primarily in relation to resources in exposed areas, hint towards lower 473 plasticity in resource utilisation of changing prey communities. This finding is also partly 
474 reflected in the predator-specific food suitability estimation (Fig. 3), which shows no significant

475 improvement for the respective species over time.

476

\section{Conclusion}

478 The structural changes in zoobenthos communities around the Åland Islands and over the past 40

479 years have not only resulted in changes of the species composition but also altered the

480 characteristics of the communities influencing their suitability as prey for the fish assemblage in

481 this area. Based on the changes of prey traits at the community level, we found that the food

482 resource suitability has increased for most of the benthic feeding predators since the 2000s. Our

483 conceptual framework based on functional traits that reflect predation-relevant morphological

484 and behavioural characteristics of prey can highlight changes in food suitability for predators

485 along changing prey communities. With no other available means to find out if the resource

486 suitability for a predator has changed over long temporal scales, in cases where there is no

487 detailed data on diet, our approach takes advantage of binary predator-prey links, available from

488 the literature, and translates them into trait-based feeding profiles of predators reflecting specific

489 affinities to certain prey traits. These can then be linked to e.g. spatiotemporal changes in the 490 functional structure (CWM) of prey communities and may serve as proxy for the food resource

491 suitability or explanatory factor for predator-prey dynamics. With stomach content data and 492 other cost and sample intensive measurements often lacking, especially on long temporal and 493 broad spatial scales, our approach can help understand altered predator-prey interactions. Being 494 independent of taxonomic species identities, our measure promotes cross-systems comparisons 495 and is applicable to all predator-prey communities. It can further deal with newly introduced and 496 invasive species, as potential food resource, that reflect similar traits of the consumer diet profile. 497

\section{Data Accessibility}

499 Data will be made available via e.g. the Dryad Digital Repository and/or online supporting 500 information files through PeerJ's system, pending acceptance of the study for publication 501

\section{Acknowledgements}


503 We thank Claire Morandin for helpful discussions during the GLMM development and Malcolm

504 Itter for general comments that improved our study. We are grateful for the constructive 505 comments of two anonymous reviewers that helped improve this study.

506

507 


\section{References}

509 Almany GR., Webster MS. 2004. Odd species out as predator reduce diversity of coral-reef

510

511

512

513

514

515

516

517

518

519

520

521

522

523

524

525

526

527

528

529

530

531

532

533

534

535

536

537

538

539

540

541

542

543

544

545

546

547 fishes. Ecology 85:2933-2937. DOI: 10.1890/03-3150.

Baker R., Buckland A., Sheaves M. 2014. Fish gut content analysis: robust measures of diet composition. Fish and Fisheries 15:170-177. DOI: 10.1111/faf.12026.

Bates D., Mächler M., Bolker B., Walker S. 2015. Fitting Linear Mixed-Effects Models Using lme4. Journal of Statistical Software 67. DOI: 10.18637/jss.v067.i01.

de Bello F., Lavorel S., Díaz S., Harrington R., Cornelissen JHC., Bardgett RD., Berg MP., Cipriotti P., Feld CK., Hering D., da Silva PM., Potts SG., Sandin L., Sousa JP., Storkey J., Wardle D a., Harrison P a. 2010. Towards an assessment of multiple ecosystem processes and services via functional traits. Biodiversity and Conservation 19:2873-2893. DOI: 10.1007/s10531-010-9850-9.

Both C., van Asch M., Bijlsma RG., van den Burg AB., Visser ME. 2009. Climate change and unequal phenological changes across four trophic levels: constraints or adaptations? Journal of Animal Ecology 78:73-83. DOI: 10.1111/j.1365-2656.2008.01458.x.

Cadotte MW., Carscadden K., Mirotchnick N. 2011. Beyond species: Functional diversity and the maintenance of ecological processes and services. Journal of Applied Ecology 48:10791087. DOI: 10.1111/j.1365-2664.2011.02048.x.

Clark CM., Flynn DFB., Butterfield BJ., Reich PB. 2012. Testing the Link between Functional Diversity and Ecosystem Functioning in a Minnesota Grassland Experiment. PLoS ONE 7. DOI: $10.1371 /$ journal.pone.0052821.

Collie JS., Wood AD., Jeffries HP. 2008. Long-term shifts in the species composition of a coastal fish community. Canadian Journal of Fisheries and Aquatic Sciences 65:13521365. DOI: 10.1139/F08-048.

De Crespin De Billy V., Usseglio-Polatera. 2002. Traits of brown trout prey in relation to habitat characteristics and benthic invertebrate communities. Journal of Fish Biology 60:687-714. DOI: $10.1006 /$ jfbi.2002.1887.

Dice LR. 1949. The Selection Index and Its Test of Significance. Evolution 3:262-265. DOI: $10.2307 / 2405563$.

Dormann CF. 2011. How to be a specialist ? Quantifying specialisation in pollination networks. Network Biology 1:1-20.

Dormann CF., Fruend J., Bluethgen N., Gruber B. 2009. Indices, graphs and null models: analyzing bipartite ecological networks. The Open Ecology Journal 2:7-24.

Dormann CF., Gruber B., Fruend J. 2008. Introducing the bipartite Package: Analysing Ecological Networks. $R$ news 8:8-11.

Dormann CF., Gruber B., Fründ J. 2008. Introducing the bipartite Package: Analysing Ecological Networks. R News 8:8-11. DOI: 10.1159/000265935.

Folke C., Carpenter S., Walker B., Scheffer M., Elmqvist T., Gunderson L., Holling CS. 2004. Regime Shifts, Resilience, and Biodiversity in Ecosystem Management. Annual Review of Ecology, Evolution, and Systematics 35:557-581. DOI: 
548

549

550

551

552

553

554

555

556

557

558

559

560

561

562

563

564

565

566

567

568

569

570

571

572

573

574

575

576

577

578

579

580

581

582

583

584

585

586

587

588

10.1146/annurev.ecolsys.35.021103.105711.

Fry B., Sherr EB. 1989. 13 C Measurements as Indicators of Carbon Flow in Marine and Freshwater Ecosystems. In: Rundel PW, Ehleringer JR, Nagy KA eds. Stable Isotopes in Ecological Research. New York, NY: Springer New York, 196-229. DOI: 10.1007/978-14612-3498-2_12.

Gagic V., Bartomeus I., Jonsson T., Taylor A., Winqvist C., Fischer C., Slade EM., SteffanDewenter I., Emmerson M., Potts SG., Tscharntke T., Weisser W., Bommarco R. 2015. Functional identity and diversity of animals predict ecosystem functioning better than species-based indices. Proceedings of the the Royal Society B 282:20142620. DOI: 10.1098/rspb.2014.2620.

Gravel D., Poisot T., Albouy C., Velez L., Mouillot D. 2013. Inferring food web structure from predator-prey body size relationships. Methods in Ecology and Evolution 4:1083-1090. DOI: $10.1111 / 2041-210 X .12103$.

Green SJ., Côté IM. 2014. Trait-based diet selection: Prey behaviour and morphology predict vulnerability to predation in reef fish communities. Journal of Animal Ecology 83:14511460. DOI: $10.1111 / 1365-2656.12250$.

Harley CDG., Hughes a. R., Hultgren KM., Miner BG., Sorte CJB., Thornber CS., Rodriguez LF., Tomanek L., Williams SL. 2006. The impacts of climate change in coastal marine systems. Ecology Letters 9:228-241. DOI: 10.1111/j.1461-0248.2005.00871.x.

Hiddink JG., Moranta J., Balestrini S., Sciberras M., Cendrier M., Bowyer R., Kaiser MJ., Sköld M., Jonsson P., Bastardie F., Hinz H. 2016. Bottom trawling affects fish condition through changes in the ratio of prey availability to density of competitors. Journal of Applied Ecology 53:1500-1510. DOI: 10.1111/1365-2664.12697.

Hinz H., Kröncke I., Ehrich S. 2005. The feeding strategy of dab Limanda limanda in the southern North Sea: linking stomach contents to prey availability in the environment. Journal of Fish Biology 67:125-145. DOI: 10.1111/j.0022-1112.2005.00918.x.

Hinz H., Moranta J., Balestrini S., Sciberras M., Pantin JR., Monnington J., Zalewski A., Kaiser MJ., Sköld M., Jonsson P., Bastardie F., Hiddink JG. 2017. Stable isotopes reveal the effect of trawl fisheries on the diet of commercially exploited species. Scientific Reports 7:6334. DOI: $10.1038 / \mathrm{s} 41598-017-06379-6$.

Hooper DU., Chapin FS., Ewel JJ., Hector A., Inchausti P., Lavorel S., Lawton JH., Lodge DM., Loreau M., Naeem S., Schmid B., Setälä H., Symstad AJ., Vandermeer J., Wardle DA. 2005. Effects of biodiversity on ecosystem functioning: a consensus of current knowledge. Ecological Monographs 75:3-35. DOI: 10.1890/04-0922.

Husseman JS., Murray DL., Power G., Mack C., Wenger CR., Quigley H. 2003. Assessing Differential Prey Selection Patterns between Two Sympatric Large Carnivores. Oikos 101:591-601. DOI: 10.1034/j.1600-0706.2003.12230.x.

Hyslop EJ. 1980. Stomach contents analysis-a review of methods and their application. J. Fish Biol. 17:411-429. DOI: 10.1111/j.1095-8649.1980.tb02775.x.

Iverson S. 2009. Tracing Aquatic Food Webs Using Fatty Acids: From Qualitative to Quantative Determination. In: Kainz M., Brett M. AM ed. Lipids in Aquatic Ecosystems. New York, 
589

590

591

592

593

594

595

596

597

598

599

600

601

602

603

604

605

606

607

608

609

610

611

612

613

614

615

616

617

618

619

620

621

622

623

624

625

626

627

628

NY: Springer New York, 281-308. DOI: 10.1007/978-0-387-89366-2_12.

Johnson AF., Gorelli G., Jenkins SR., Hiddink JG., Hinz H. 2014. Effects of bottom trawling on fish foraging and feeding. Proceedings of the Royal Society B: Biological Sciences 282:20142336-20142336. DOI: 10.1098/rspb.2014.2336.

Kelly J., Scheibling R. 2012. Fatty acids as dietary tracers in benthic food webs. Marine Ecology Progress Series 446:1-22. DOI: 10.3354/meps09559.

Kerr SR. 1974. Theory of size distribution in ecological communities. J. Fish. Res. Board Can. 31:1859-1862.

Klecka J., Boukal DS. 2013. Foraging and vulnerability traits modify predator-prey body mass allometry: Freshwater macroinvertebrates as a case study. Journal of Animal Ecology 82:1031-1041. DOI: 10.1111/1365-2656.12078.

Kuznetsova A., Brockhoff PB., Christensen RHB. 2016. lmerTest: Tests in Linear Mixed Effects Models. R package version 2.0-30. :https:/CRAN.R-project.org/package=lmerTest.

Laliberté E., Legendre P., Shipley B. 2014. FD: measuring functional diversity from multiple traits, and other tools for functional ecology. R package version 1.0-12.

Lappalainen A., Rask M., Koponen H., Vesala S. 2001. Relative abundance, diet and growth of perch(Perca fluviatilis) and roach(Rutilus rutilus) at Tvaerminne, northern Baltic Sea, in 1975 and 1997: responses to. Boreal Environment Research 6:107-118.

Mattila J., Bonsdorff E. 1988. A quantitative estimation of fish predation on shallow soft bottom benthos in SW Finland. Kieler Meeresforschung 6:111-125.

Mattila J., Bonsdorff E. 1989. The impact of fish predation on shallow soft bottoms in brackish waters (SW Finland); an experimental study. Netherlands Journal of Sea Research 23:6981. DOI: 10.1016/0077-7579(89)90044-6.

Mouillot D., Villéger S., Scherer-Lorenzen M., Mason NWH. 2011. Functional structure of biological communities predicts ecosystem multifunctionality. PLOS ONE 6. DOI: 10.1371/journal.pone.0017476.

Nagelkerke LAJ., Rossberg AG. 2014. Trophic niche-space imaging, using resource and consumer traits. Theoretical Ecology 7:423-434. DOI: 10.1007/s12080-014-0229-5.

Olsson J., Bergström L., Gårdmark A. 2013. Top-Down Regulation, Climate and Multi-Decadal Changes in Coastal Zoobenthos Communities in Two Baltic Sea Areas. PLoS ONE 8:e64767. DOI: 10.1371/journal.pone.0064767.

Persson L. 1983. Effects of Intra- and Interspecific Competition on Dynamics and Size Structure of a Perch Perca Fluviatilis and a Roach Rutilus rutilus Population. Oikos 41:126-132. DOI: $10.2307 / 3544354$.

Petchey OL., Gaston KJ. 2006. Functional diversity: Back to basics and looking forward. Ecology Letters 9:741-758. DOI: 10.1111/j.1461-0248.2006.00924.x.

Pimm SL., Lawton JH., Cohen JE. 1991. Food Web Patterns and Their Consequences. Nature 350:669-674. DOI: 10.1038/350669a0.

Pyke GH., Pulliam HR., Charnov EL. 1977. Optimal foraging: a selective review of theory and tests. The Quarterly Review of Biology 52:137-154. 
629

630

631

632

633

634

635

636

637

638

639

640

641

642

643

644

645

646

647

648

649

650

651

652

653

654

655

656

657

658

659

660

661

662

663

664

665

666

667

668

Quillien N., Nordström MC., Schaal G., Bonsdorff E., Grall J. 2016. Opportunistic basal resource simplifies food web structure and functioning of a highly dynamic marine environment. Journal of Experimental Marine Biology and Ecology 477:92-102. DOI: 10.1016/j.jembe.2016.01.010.

R Development Core Team. 2013. R: A language and environment for statistical computing. R Foundation for Statistical Computing, Vienna, Austria. www.r-project.org.

Rodríguez-Lozano P., Verkaik I., Maceda-Veiga A., Monroy M., de Sostoa A., Rieradevall M., Prat N. 2016. A trait-based approach reveals the feeding selectivity of a small endangered Mediterranean fish. Ecology and Evolution 6:3299-3310. DOI: 10.1002/ece3.2117.

Rossberg AG., Brännström Å., Dieckmann U. 2010. How trophic interaction strength depends on traits. Theoretical Ecology 3:13-24. DOI: 10.1007/s12080-009-0049-1.

Rusch A., Birkhofer K., Bommarco R., Smith HG., Ekbom B. 2015. Predator body sizes and habitat preferences predict predation rates in an agroecosystem. Basic and Applied Ecology 16:250-259. DOI: 10.1016/j.baae.2015.02.003.

Schmitz OJ., Barton BT. 2014. Climate change effects on behavioral and physiological ecology of predator-prey interactions: Implications for conservation biological control. Biological Control 75:87-96. DOI: 10.1016/j.biocontrol.2013.10.001.

Snickars M., Weigel B., Bonsdorff E. 2015. Impact of eutrophication and climate change on fish and zoobenthos in coastal waters of the Baltic Sea. Marine Biology 162:141-151. DOI: $10.1007 / \mathrm{s} 00227-014-2579-3$.

Spitz J., Ridoux V., Brind'Amour A. 2014. Let's go beyond taxonomy in diet description: testing a trait-based approach to prey-predator relationships. Journal of Animal Ecology 83:11371148. DOI: $10.1111 / 1365-2656.12218$.

Thébault E., Loreau M. 2003. Food-web constraints on biodiversity-ecosystem functioning relationships. Proceedings of the National Academy of Sciences of the United States of America 100:14949-14954. DOI: 10.1073/pnas.2434847100.

Tilman D., Knops J., Wedin D., Reich P., Ritchie M., Siemann E. 1997. The influence of functional diversity and composition on ecosystem processes. Science 277:1300-1302. DOI: $10.1126 /$ science.277.5330.1300.

Törnroos A., Bonsdorff E. 2012. Developing the multitrait concept for functional diversity: Lessons from a system rich in functions but poor in species. Ecological Applications 22:2221-2236.

Tylianakis JM., Didham RK., Bascompte J., Wardle DA. 2008. Global change and species interactions in terrestrial ecosystems. Ecology Letters 11:1351-1363. DOI: 10.1111/j.14610248.2008.01250.x.

Vadas RL. 1977. Preferential Feeding : An Optimization Strategy in Sea Urchins. Ecological Monographs 47:337-371.

Walther GR. 2010. Community and ecosystem responses to recent climate change. Philosophical Transactions of the Royal Society B: Biological Sciences 365:2019-2024. DOI: 10.1098/rstb.2010.0021. 
669 Weigel B., Andersson HC., Meier HEM., Blenckner T., Snickars M., Bonsdorff E. 2015. Long-

670

671

672

673

674

675

676

677

678

679

680

681

682

683

684

685

686

687

688 term progression and drivers of coastal zoobenthos in a changing system. Marine Ecology Progress Series 528:141-159. DOI: 10.3354/meps11279.

Weigel B., Blenckner T., Bonsdorff E. 2015. Data from: Maintained functional diversity in benthic communities in spite of diverging functional identities. Oikos. DOI: doi:10.5061/dryad.6hc8q.

Weigel B., Blenckner T., Bonsdorff E. 2016. Maintained functional diversity in benthic communities in spite of diverging functional identities. Oikos 125:1421-1433. DOI: 10.1111/oik.02894.

Winkler HM., Debus L. 1996. Is the polychaete Marenzelleria viridis an important food item for fish? Proceedings of the 13th Symposium of the Baltic Marine Biologists:147-151.

Yen JDL., Cabral RB., Cantor M., Hatton I., Kortsch S., Patrício J., Yamamichi M. 2016. Linking structure and function in food webs: Maximization of different ecological functions generates distinct food web structures. Journal of Animal Ecology 85:537-547. DOI: 10.1111/1365-2656.12484.

Yletyinen J., Bodin Ö., Weigel B., Nordström MC., Bonsdorff E., Blenckner T. 2016. Regime shifts in marine communities: a complex systems perspective on food web dynamics. Proceedings of the Royal Society B: Biological Sciences 283:20152569. DOI: 10.1098/rspb.2015.2569. 


\title{
Figure 1 (on next page)
}

Conceptual illustration of different steps involved in the calculation of the trait-based diet spectrum

\begin{abstract}
(A) starting with binary predator-prey matrix PP with predator species $i$ and prey species $j$, (B) building preytrait by prey-species matrix $T$ for each predator $i,(C)$ calculating trait-based diet spectrum DS for every predator $i$ and prey trait $k$,by relating the sum of each prey trait in predator's diet to the number of species in its diet, as specified in equation 1 . Here exemplified with red highlighted steps for predator $i_{1}$. DS values for trait $k_{1}=1$ would indicate that all prey items of predator $i_{1}$ express trait $k_{1}$.
\end{abstract}




\begin{tabular}{|c|c|c|c|c|c|c|}
\hline \multirow[t]{2}{*}{ A } & \multicolumn{6}{|c|}{ Predator $i=1, \ldots, m$} \\
\hline & $\mathbf{P P}$ & $i_{1}$ & $i_{2}$ & $i_{3}$ & $\ldots$ & $i_{m}$ \\
\hline & $j_{1}$ & 1 & 0 & 1 & $\ldots$ & 1 \\
\hline & $j_{2}$ & 1 & 1 & 1 & $\ldots$ & 0 \\
\hline & $i$ & 0 & 0 & & & \\
\hline & $\sqrt{3}$ & 0 & 0 & 0 & $\cdots$ & 1 \\
\hline & $\vdots$ & $\vdots$ & $\vdots$ & $\vdots$ & $\cdots$ & $\vdots$ \\
\hline & $j_{n}$ & 0 & 0 & 1 & $\ldots$ & 1 \\
\hline
\end{tabular}

B

\begin{tabular}{|c|c|c|c|c|c|}
\hline \multicolumn{6}{|c|}{ Trait $k=1, \ldots, t$} \\
\hline$T_{i}$ & $k_{1}$ & $k_{2}$ & $k_{3}$ & $\ldots$ & $k_{t}$ \\
\hline$j_{1}$ & 1 & 1 & 1 & $\ldots$ & 0 \\
\hline$j_{2}$ & 1 & 1 & 0 & $\cdots$ & 0 \\
\hline$j_{3}$ & 1 & 0 & 0 & $\cdots$ & 1 \\
\hline & $\vdots$ & $\vdots$ & $\vdots$ & $\ldots$ & $\vdots$ \\
\hline$j_{n}$ & 1 & 0 & 1 & $\ldots$ & 1 \\
\hline
\end{tabular}

C

Sum of prey trait in diet

Trait $k$

Number of species in diet

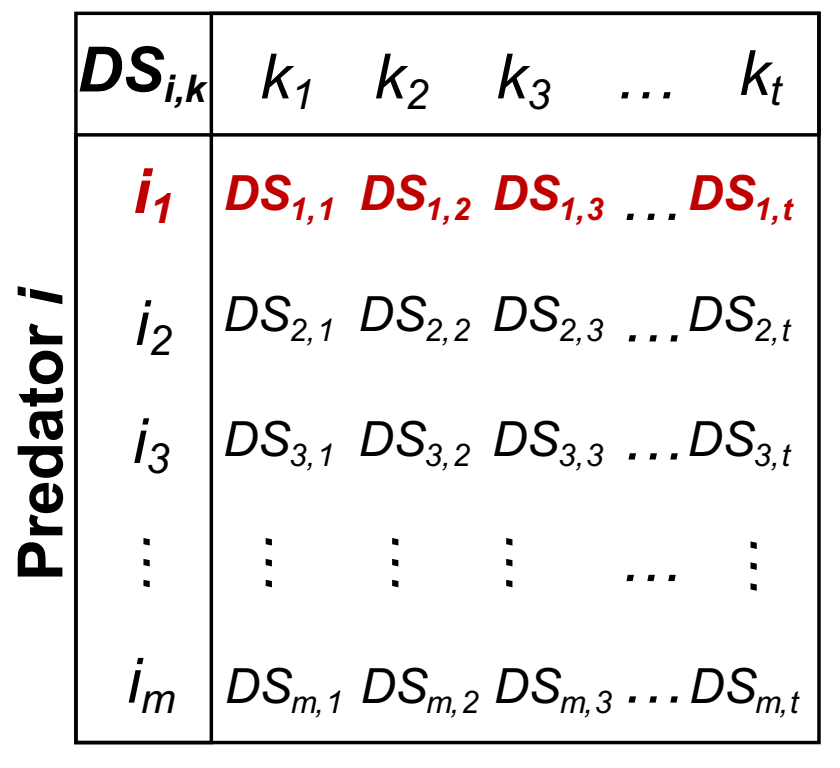




\section{Figure 2 (on next page)}

Trait-based diet spectrum of fish community.

Species are sorted by their similarity in diet spectrum, where similarity-groupings are indicated through the dendrogram. Colour saturation and size indicate the level of trait specific feeding affinity, with ' 1 ' indicating trait category is always being preyed on and ' 0 ' indicating never being preyed on. 


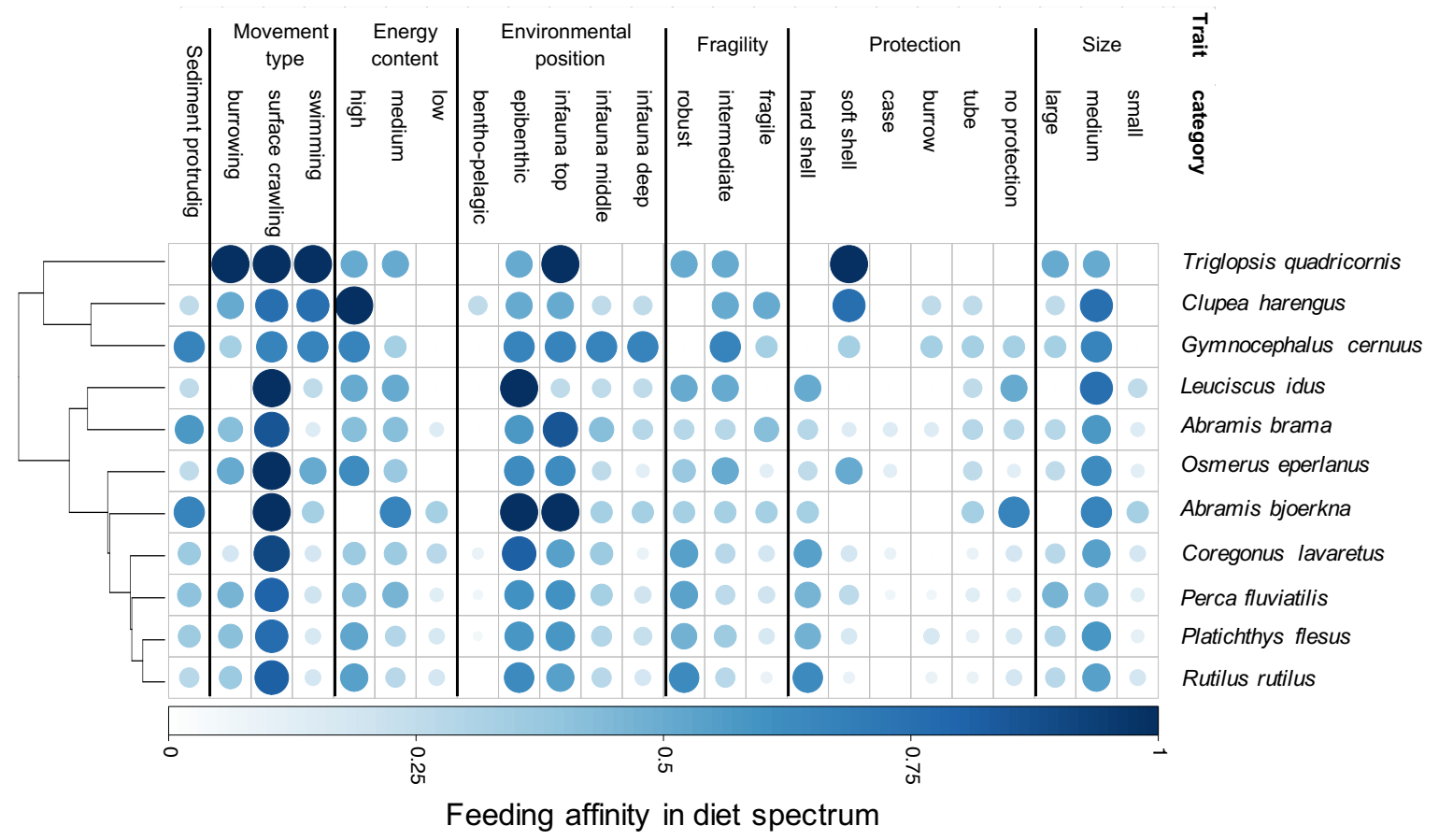


Figure 3 (on next page)

Species-specific linear mixed-effect model results.

Colours indicate direction of parameter estimates, with blue and orange reflecting positive and negative estimates respectively. All years are compared against 1973. Significance levels of model parameters for each species are indicated with stars following the significance coding: 0 '***' $0.001^{\prime * * \prime} 0.01^{\prime} *^{\prime} 0.05^{\prime} .{ }^{\prime} 0.11^{\prime \prime} 1$ 
PeerJ

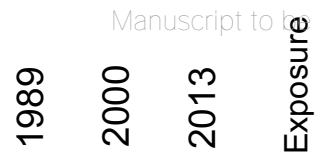

Abramis bjoerkna

Abramis brama

Clupea harengus

Coregonus lavaretus

Gymnocephalus cernuus

Leuciscus idus

Osmerus eperlanus

Perca fluviatilis

Platichthys flesus

Rutilus rutilus

Triglopsis quadricornis

0.14

0.11

*** $\quad * * *$

0.17

*

**

0.08

**

***

0.06

0.03

* $\quad * *$

*

**

0

*

$\star *$

$-0.03$ 
Figure 4 (on next page)

Functional diversity - food resource suitability relationship.

(A) Development of functional dispersion (FDis) of all sampled prey assemblages $(n=16)$ over time; (B) relationship between food suitability proxy $S$ and functional dispersion (FDis) of prey communities. Here $S$ is the mean standardized predictor variable for each prey assemblage at all sites and all sampled years, as applied in the community mixed effect model. Positive relationship is highlighted with a linear model (model estimate $=0.074, p<$ 0.0001 , adj. $\left.r^{2}=0.53\right)$. 
A $\quad$ PeerJ

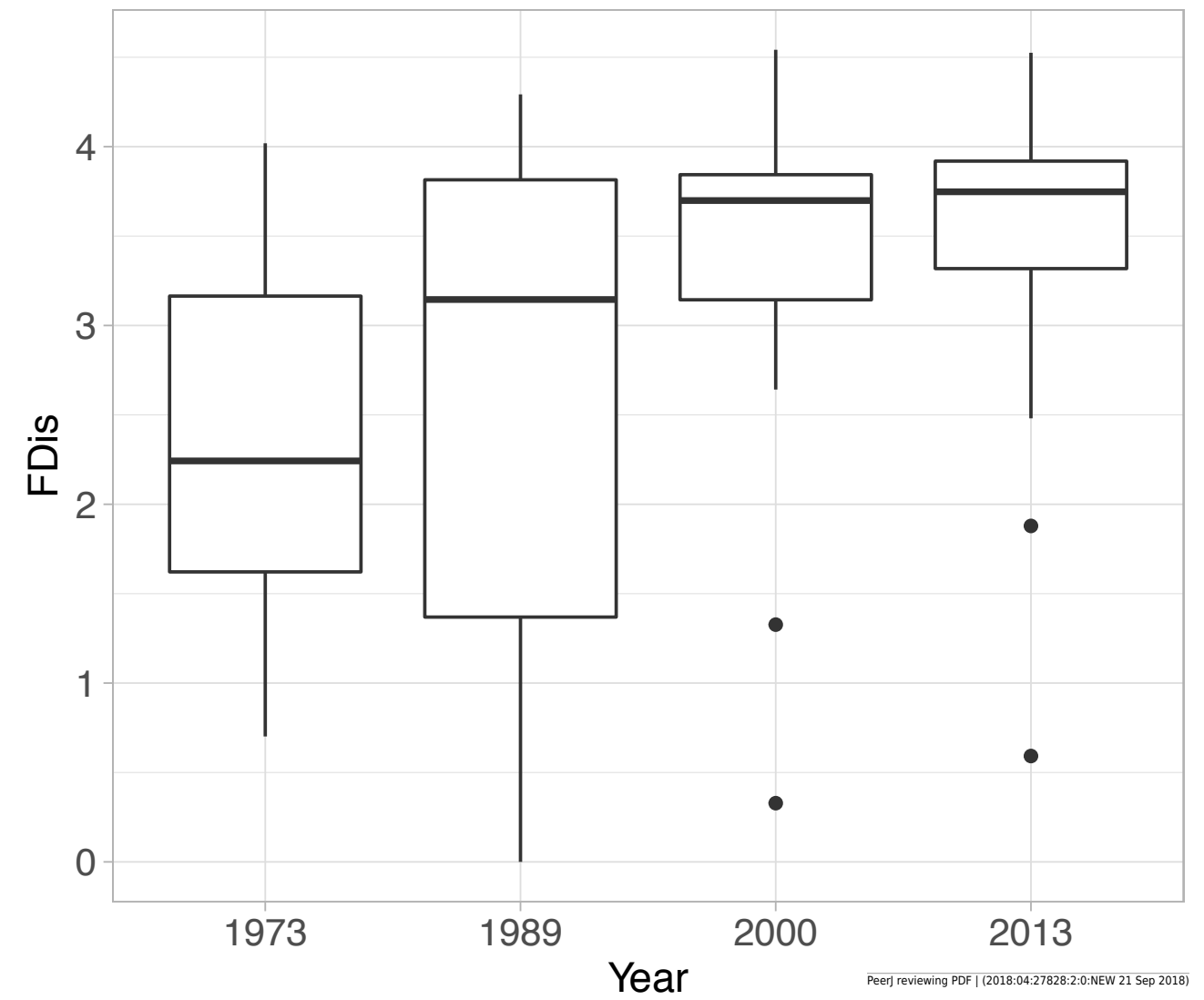

B B $^{\text {nuscript to be reviewed }}$

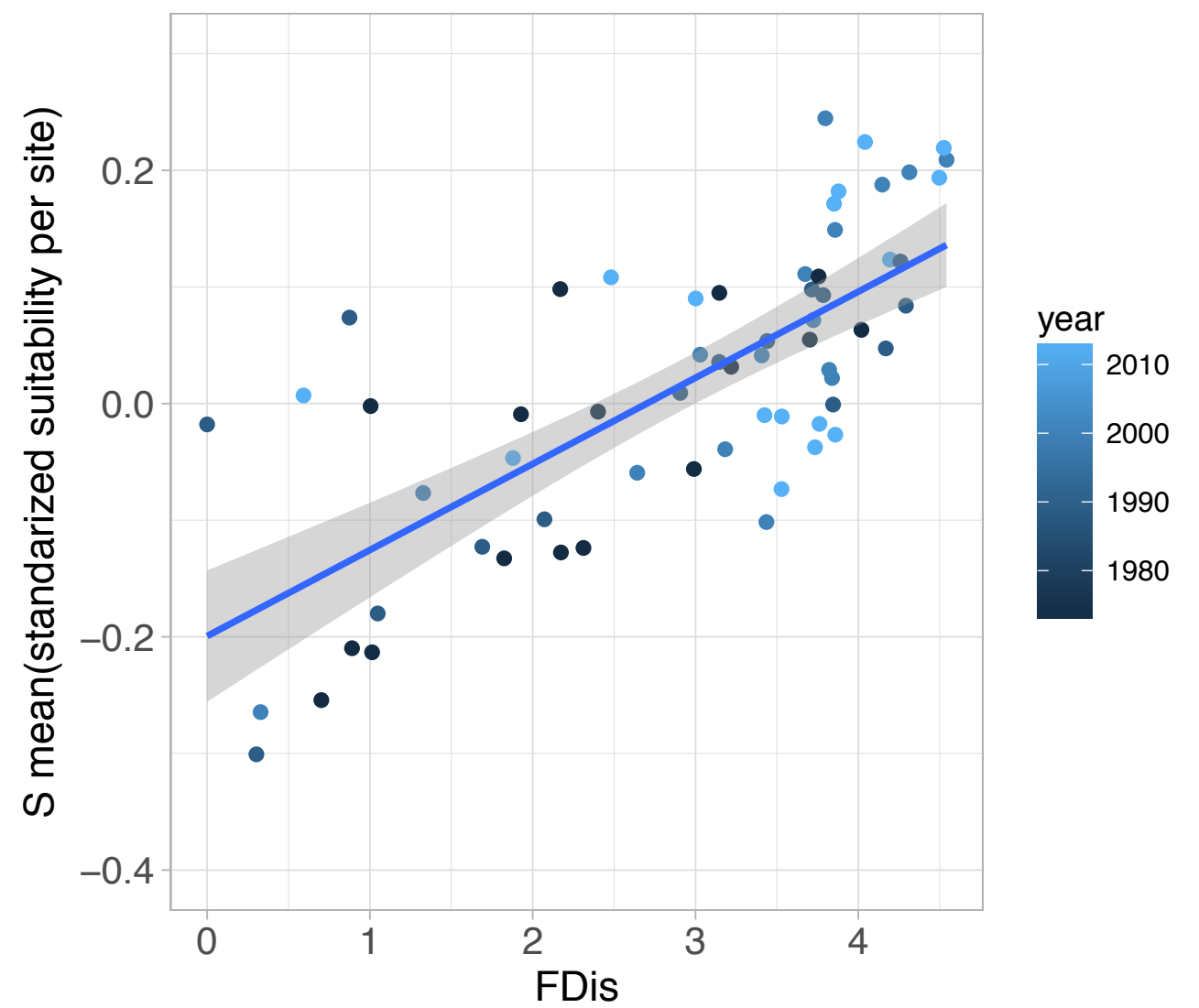


Figure $\mathbf{5}$ (on next page)

Predation linkage network structure

(A) sum of interactions between predatory fish and the available (trait-based) zoobenthic prey for all sites, (B) 'Proportional similarity' reflecting the ratio between resource use and availability, acting as a measure of specialisation. Each year comprises 8 exposed (orange) and 8 sheltered (blue) sites. 


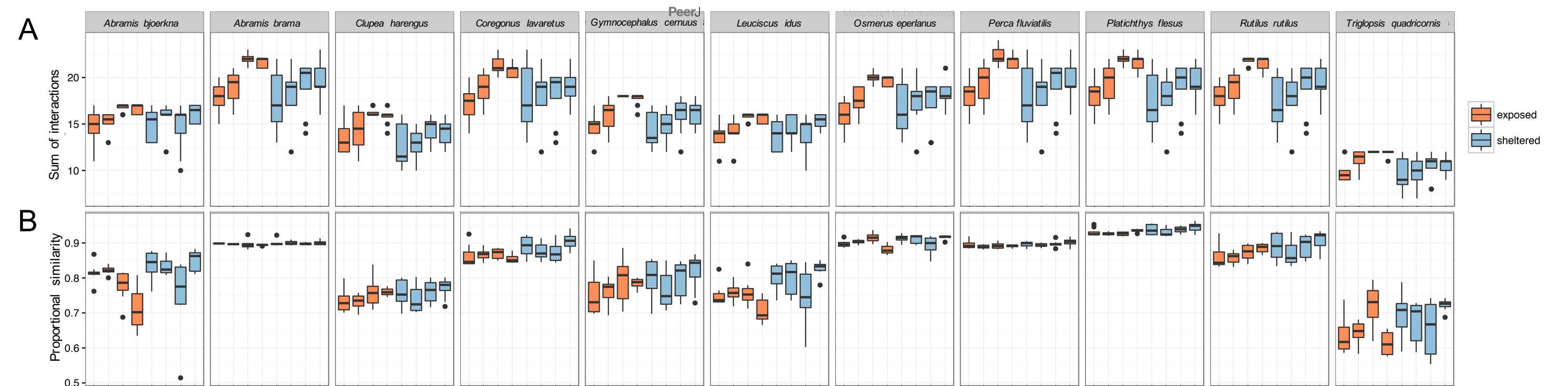




\section{Table $\mathbf{1}$ (on next page)}

Benthic-feeding fish predator assemblage (HELCOM 2012, Snickars et al. 2015) 


\begin{tabular}{|c|c|c|c|c|}
\hline Family & Species & Common name & Origin & $\begin{array}{c}\text { Warm/cold- } \\
\text { water }\end{array}$ \\
\hline Clupeidea & Clupea harengus & Herring & Marine & cold \\
\hline Cottidae & Triglopsis quadricornis & Fourhorn sculpin & Freshwater & cold \\
\hline Cyprinidae & Abramis bjoerkna & Silver bream & Freshwater & warm \\
\hline Cyprinidae & Abramis brama & Bream & Freshwater & warm \\
\hline Cyprinidae & Leuciscus idus & Ide & Freshwater & warm \\
\hline Cyprinidae & Rutilus rutilus & Roach & Freshwater & warm \\
\hline Osmeridae & Osmerus eperlanus & Smelt & Freshwater & cold \\
\hline Percidae & Gymnocephalus cernuus & Ruffe & Freshwater & warm \\
\hline Percidae & Perca fluviatilis & Perch & Freshwater & warm \\
\hline Pleuronectidae & Platichthys flesus & Flounder & Marine & - \\
\hline Salmonidae & Coregonus lavaretus & Whitfish & Freshwater & cold \\
\hline
\end{tabular}
1 


\section{Table 2 (on next page)}

List of included functional traits (7) and trait categories (24). 


\begin{tabular}{|c|c|c|c|}
\hline Trait & Category & & Reference \\
\hline \multirow[t]{3}{*}{ Maximum size } & small & $1-5 \mathrm{~mm}$ & 1,2 \\
\hline & medium & $6-30 \mathrm{~mm}$ & \\
\hline & large & $>30 \mathrm{~mm}$ & \\
\hline \multirow[t]{6}{*}{ Protection } & no protection & & 1 \\
\hline & tube & & \\
\hline & burrow & & \\
\hline & case & & \\
\hline & soft shell & & \\
\hline & hard shell & & \\
\hline \multirow[t]{2}{*}{ Fragility } & fragile & & 1 \\
\hline & $\begin{array}{l}\text { intermediate } \\
\text { robust }\end{array}$ & & \\
\hline \multirow[t]{2}{*}{ Environmental position } & infauna deep & $>5 \mathrm{~cm}$ & 1 \\
\hline & $\begin{array}{l}\text { infauna middle } \\
\text { infauna top } \\
\text { epibenthic } \\
\text { benthic pelagic }\end{array}$ & $\begin{array}{l}\text { within } 2-5 \mathrm{~cm} \\
\text { top } 2 \mathrm{~cm}\end{array}$ & \\
\hline \multirow[t]{3}{*}{ Energy content } & low & $<1.7 \mathrm{~kJ} / \mathrm{g}$ wet weight & 2 \\
\hline & medium & $1.7-3.4 \mathrm{~kJ} / \mathrm{g} \mathrm{wwt}$ & \\
\hline & high & $3.4-5.1 \mathrm{~kJ} / \mathrm{g} w w t$ & \\
\hline \multirow[t]{2}{*}{ Movement } & swimming & & 1 \\
\hline & $\begin{array}{l}\text { surface crawling } \\
\text { burrowing }\end{array}$ & & \\
\hline Protruding & sediment protruc & & 3 \\
\hline
\end{tabular}

1 Törnroos and Bonsdorff 2012

2 Weigel et al. 2016

3 Expert judgment 


\section{Table 3(on next page)}

Linear mixed-effect model results and significant approximations for the community model including all eleven fish species. 


\begin{tabular}{lcccc}
\hline Fixed effects & $\begin{array}{c}\text { parameter } \\
\text { estimate }\end{array}$ & t-value & p-value & \\
\hline $\begin{array}{l}\text { (Intercept) } \\
1989\end{array}$ & -0.0319 & -0.207 & 0.8370 & \\
2000 & -0.0308 & -2.024 & 0.0430 & $*$ \\
2013 & 0.0905 & 5.945 & $<0.0001 \quad * * *$ \\
Exposure & 0.1113 & 7.31 & $<0.0001 \quad * * *$ \\
\hline
\end{tabular}

1 